\title{
Erratum
}

\section{Complications of Intertrochanteric Rotational Osteotomy}

Skeletal Radiology (1983) 10:258-261

Ethan M. Braunstein, M.D. ${ }^{1}$, Barbara N. Weissman, M.D. ${ }^{1}$, J. Leland Sosman, M.D. ${ }^{1}$, and Michael Drew, M.D. ${ }^{2}$

Departments of ${ }^{1}$ Radiology and ${ }^{2}$ Orthopaedics, Harvard Medical School, Brigham and Women's Hospital, Boston, Massachusetts, USA

On page 261, right column, the last sentence should read:

The absence of radiographic changes does not assure a successful outcome for rotational osteotomy. 